\title{
ENSINAR CRIMINOLOGIA: ENTRE VON LISZT E BARATTA
}

\author{
TO TEACH CRIMINOLOGY: BETWEEN VON LISZT AND BARATTA
}

Mário Lúcio Garcez Calil

Doutor em Direito pela Faculdade de Direito de Bauru (CEUB-ITE). Estágios de Pós-Doutorado (bolsista PDJCNPQ e PNPD-CAPES) no Programa de Pós-Graduação em Direito do Centro Universitário Eurípides de Marília (PPGD/UNIVEM.) Professor Adjunto IV da Universidade Estadual de Mato Grosso do Sul (UEMS).

E-mail: mario.calil@yahoo.com.br

\section{Samyra Haydêe Dal Farra Naspolini}

Doutora em Direito pela Pontifícia Universidade Católica de São Paulo, Mestre em Direito pela Universidade Federal de Santa Catarina; Docente e pesquisadora e professora permanente do Programa de Mestrado em Direito na Sociedade da Informação e do Curso de Graduação em Direito do Centro Universitário das Faculdades

Metropolitanas Unidas (FMU-SP). Docente e pesquisadora permanente do Mestrado em Direito do Centro Universitário de Marília - UNIVEM. Editora da Revista Em Tempo do UNIVEM. Membro associado e Diretora Executiva do Conselho de Pesquisa e Pós Graduação em Direito - CONPEDI e da Associação Brasileira de Ensino do Direito - ABEDi. E-mail: samyranaspolini@gmail.com

\section{Horácio Wanderlei Rodrigues}

Doutor e Mestre em Direito pela UFSC. Estágios de Pós-Doutorado em Filosofia/UNISINOS e em Educação/UFRGS. Professor Permanente e Coordenador do PPGD/UNIVEM e Professor Convidado do PPGD/UNICURITIBA. Professor Titular (aposentado) do DIR/UFSC. Membro do Instituto Iberomericano de Derecho Procesal. Sócio fundador do CONPEDI e da ABEDi. Bolsista de Produtividade em Pesquisa do CNPq. E-mail: horaciowr@gmail.com

Recebido em: 21/07/2020 Aprovado em: 09/11/2020

RESUMO: O objetivo do presente trabalho é estudar as possibilidades da Criminologia Crítica na Educação Jurídica brasileira, a partir dos modelos de Ciência Integrada do Direito Penal, por meio do procedimento bibliográfico, de abordagem qualitativa, utilizando-se, quanto à escrita, o método dedutivo. No modelo original de Ciência Integrada do Direito Penal, a Criminologia ocupava um papel de ciência "auxiliar" à Dogmática Penal. Em sua "nova" formatação, a referida ciência ocupa um status central e autônomo. O trabalho é justificável, pela necessidade de se estudar o Direito Penal de maneira integrada à realidade e à complexidade social. Conclui que, para que se possa dar concretude ao novo modelo integrado, a Criminologia deve ser ensinada como saber crítico, no Curso de Direito.

Palavras-chave: Ciência Integrada. Direito Penal. Criminologia. Curso de Direito. Educação Jurídica. 


\begin{abstract}
The purpose of the present study is to study the possibilities of the critical criminology in Brazilian legal education, using the integrated models of criminal law, through the bibliographic procedure, with a qualitative approach, using the deductive method as regards of the writing. In the original integrated model criminal law, criminology played a role of an "auxiliary" science to criminal dogmatic. In its "new" formatting, such science occupies a central and autonomous status. The work is justifiable, due to the need to study criminal law in an integrated way to reality and social complexity. In conclusion, in order to give concreteness to the new integrated model, criminology should be taught as a critical knowledge in the law schools.
\end{abstract}

Keywords: Integrated Science. Criminal Law. Criminology. Law Schools. Legal Education.

SUMÁRIO: Introdução. 1 O papel da criminologia no modelo original de "Ciência conjunta do Direito Penal". 2 O papel da criminologia no "novo" modelo integrado de ciências penais. 3 O ensino da criminologia crítica nos cursos de direito a partir do "novo" modelo integrado de ciências penais. Conclusão. Referências.

\title{
INTRODUÇÃO
}

No modelo original de Ciência Integrada do Direito Penal, formulado por Von Liszt, a Criminologia ocupava um papel "auxiliar" em relação à Dogmática Penal. Em sua "nova" formatação, construída, especialmente, por Alessandro Baratta, a referida ciência ocupa um status central e autônomo em relação ao Direito Penal e à Política Criminal.

Nesse sentido, o objetivo do presente trabalho será estudar as possibilidades da Criminologia Crítica, como Sociologia do Direito Penal, na Educação Jurídica brasileira, a partir dos referidos modelos de Ciências Penais Integradas, o que se fará por meio do procedimento bibliográfico, de abordagem qualitativa. Quanto à escrita, utilizar-se-á o método dedutivo.

A pesquisa se justifica pela necessidade de o estudo do Direito Penal manter-se integrado à realidade e à complexidade social, que são alguns dos objetos da Criminologia Crítica.

O trabalho será dividido em três partes: o papel da Criminologia no modelo original de "Ciência Conjunta do Direito Penal"; o papel da Criminologia no "novo" modelo integrado de Ciências Penais; e, finalmente, o ensino da Criminologia Crítica nos Cursos de Direito a partir do "novo" modelo integrado de Ciências Penais.

\section{O PAPEL DA CRIMINOLOGIA NO MODELO ORIGINAL DE “CIÊNCIA CONJUNTA DO DIREITO PENAL"}

O Direito é um fenômeno social complexo. Deve, portanto, ser estudado e trabalhado tendo em vista essa complexidade, que se demonstra qualificada no que concerne ao Direito Penal, pois esse "ramo" do Direito é o responsável por lidar com ações humanas indesejadas, bem como com várias garantias materiais e processuais do agente.

Percebida essa complexidade, Franz Von Liszt ${ }^{1}$ foi o primeiro a pensar nas inter-relações entre as bases do Direito Criminal, em um modelo tripartido, que chamou de "Ciência Conjunta do

1 Sobre Franz Von Liszt: "Nasceu a 2 de março de $1851 \mathrm{em}$ Vienna. Cursou as universidades de Göttingen e Heidelberg. Habilitou-se em 1875 como Privat-docent de Direito Penal na universidade de Graz. Em 1879 foi admittido como professor de Direito Penal e de processo civil na universidade de Giessen e em 1882 na de Marburg; d'ahi passou em 1889 para a de Halle, como professor de Direito Penal e de Direito Internacional. Disputado, como Savigny, pelas universidades da Allemanha, não pôde aceitar os convites das de Bonn, Jena e Vienna. Juntamente com Dochow (substituído depois de sua morte por Lilienthal), fundou em 1881 a Zeitschrift fur, gesammte Strafrechtswissenschaft para servir de orgão à nova direcção scientifica em opposição ao espírito e às idéas capitães da escola classica, que então preponderava, ou antes dominava exclusivamente na Allemanha. Com os professores

Revista de Direito Brasileira | Florianópolis, SC | v. 26 | n. 10 | p. 471-483 | Mai./Ago. 2020 
Direito Penal" (gesamte Strafrechtwissenschaft) ${ }^{2}$, compreendendo a Ciência do Direito Penal, a Criminologia e a Política Criminal (DIAS, 1999, p. 24).

O surgimento do referido modelo, em decorrência da evidente complexidade do Direito Criminal, admite ser a Dogmática Penal insuficiente para entender o fenômeno da criminalidade, bem como para tratá-lo. Desse modo, soma ao Direito Penal os saberes da Política Criminal e da Criminologia.

O modelo de Ciência Criminal Integrada de Liszt determinava que o Sistema de Justiça Criminal deveria ser o objeto de um conhecimento que se distanciasse progressivamente mais da Criminologia Tradicional, abordando a teoria e a Sociologia do Direito Penal, em sentido amplo (BARATTA, 2004, p. 168-169).

Esse modelo abrangia os processos institucionais e informais de criminalização, a exemplo das reações ao crime pela opinião pública, de modo que poderia se estender até mesmo ao estudo de Dogmática Penal, considerada, nesse diapasão, em seu papel de corpo constitutivo do sistema penal (BARATTA, 2004, p. 169).

Note-se, porém, que o referido modelo preocupava-se, assim como a Criminologia Etiológica, com a figura do criminoso, com o crime em si e, somente por via oblíqua, buscava trabalhar alguns dos formatos de reação social ao desvio punível, bem como tinha a Dogmática Penal como "ponto de partida".

A Criminologia de paradigma etiológico definia o objeto da Criminologia como sendo a busca das causas e dos fatores da criminalidade.

Tal Criminologia, denominada de Criminologia Positivista, cumpria a função de ciência auxiliar da Dogmática Penal, munindo-a de conhecimentos antropológicos, psicológicos e sociológicos para a construção dos conceitos dogmáticos de interpretação da lei penal, bem como da sua operacionalização para ser aplicada pelas agências judiciárias.

Como uma ciência explicativa, que se utiliza do método de investigação empírico, buscava desenvolver as suas teorias sobre a criminalidade, através de pesquisas realizadas com indivíduos condenados nas prisões ou nos manicômios judiciais. Desta forma, as conclusões nas quais a Criminologia sempre embasou suas teorias foram fruto de investigações realizadas com indivíduos

van Hamel de Amsterdam e Prins de Bruxellas, promoveu a fundação da União Internacional de Direito Penal, destinada, segundo rezam os seus estatutos, a estudar a criminalidade e a repressão tanto no ponto de vista social como no ponto de vista jurídico e a trabalhar pela adopção deste, concepção e de suas consequencias na sciencia e na legislação penaes. A seus esforços se deve a fundação de um Kriminalistisches Seminar com riquíssima bibliotheca, em 1888, em Marburg, donde passou para Halle. Instituto destinado a estudos especiaes sobre o Direito Penal, a sua influência benefica se revela pelos seus numerosos trabalhos publicados periodicamente em fascículos e que já formam grossos volumes. Extensa é a lista de suas obras. O seu tratado de Direito Penal, publicado pela primeira vez em 1881, teve 7 edições até 1895, sempre aperfeiçoadas pelo autor de modo a acompanhar o progresso da sciencia e a pôr o livro ao corrente da litteratura e da jurisprudencia. [...] Falecido a 21 de junho de 1919, em Seeheim, Áustria". (PEREIRA, 1899, p. XXIX-XXX).

2 "O Direito Penal e a política criminal são sciencias do jurísconsulto.[...] Só pela união e mutua influencia do Direito Penal e da política criminal completa-se a idéa da sciencia do Direito Penal (das sciences pênales, como dizem os Francezes ) Oríal-as, desenvolve-las, transmiti-las, é a missão do criminalista, não é missão do medico, do sociólogo, do estatiscista. Desde que não actue o pensamento de que o Direito Penal e a politica criminal são dous ramos do mesmo tronco, duas partes do mesmo todo, que se tocam, se cruzam e se frutificam, e que, sem esta relação de mutua dependência, se desnaturam, é inevitável a decadência do Direito Penal. Será o perfeito conhecimento do direito vigente em todas as suas ramificações, sem completa posse da technica da legislação, sem o rigoroso freio do raciocínio logico-jurídico, a política criminal degenera em um racionalismo estéril a fluctuar desorientado sobre as ondas. Por outro lado, o Direito Penal perde-se em um formalismo infecundo e estranho à vida, si não for penetrado e guiado pela convicção de que o crime não é somente um idéia, mas um facto do mundo dos sentidos, um facto gravíssimo na vida assim do individuo como da sociedade; que a pena não existe por amor delia mesma, mas tem o seu fundamento e o seu objectivo na protecção de interesses humanos. Sem uma sciencia do Direito Penal voltada para a vida e ao mesmo tempo adstricta ao rigor das formas, a legislação penal convertese em um jogo das opiniões do dia não apuradas, e a administração da justiça em um ofício exercido com tédio. E somente da sciencia que o Direito Penal e a administração da justiça recebem a força vivificadora". (VON LISZT, 1899, p. 105).

Revista de Direito Brasileira | Florianópolis, SC | v. 26 | n. 10 | p. 471-483 | Mai./Ago. 2020 
que já haviam sido capturados pelas engrenagens do sistema penal. Além de uma expressa aceitação das definições legais como determinantes de seu objeto, ou seja, uma expressa dependência da Criminologia em face da Dogmática Penal, tal atitude revela também a função legitimante do sistema penal desempenhada pela Criminologia. ${ }^{3}$

O Iluminismo do século XVIII e a Revolução Científica do século XIX revelaram os dois paradigmas mais importantes da Criminologia: o classicismo e o positivismo. O questionamento dessas duas doutrinas é que gerou o debate, característico do século XX, e a dúvida cobriu as velhas certezas sobre a natureza do crime e o papel do Sistema de Justiça Criminal (YOUNG, 2002, p. 58-59).

Assim, a crise da Criminologia é a mesma crise da modernidade: “[...] os pilares gêmeos de razão e progresso do projeto modernista, a aplicação da lei no controle e arbitragem dos assuntos humanos e a intervenção do governo para construir uma ordem social justa vacilam sob o peso de suas próprias contradições e ineficiências" (YOUNG, 2002, p. 58).

Em decorrência da "crise" da Criminologia Etiológica, o modelo de Ciências Criminais Integradas, tal qual formulado por Von Liszt, também entrou em decadência, especialmente em decorrência do fato de que não era mais capaz de trabalhar coerentemente o Direito Criminal em uma sociedade cada vez mais caracterizada pela complexidade.

A Criminologia "Positiva" foi estudada durante a maior parte do século XX. Em determinado momento, todavia, recebeu nova modelagem, passando a julgar o Direito Penal e sua própria roupagem, passando a não existir em si e per si, mas, sim, a ser socialmente construída, convertendo o sistema penal em seu objeto e problemática (ANDRADE, 2012, p. 343-344).

A Criminologia Etiológica e o Direito Penal dogmático são denunciados por sua "função instrumentalizadora e legitimadora da seletividade". Nasce uma nova problemática para a Política Criminal, concernente à prisão e ao sistema penal. Antes um "saber auxiliar do Direito Penal", torna-se um saber crítico, externo ao modelo integrado (ANDRADE, 2012, p. 344-345).

Assim, a Criminologia deixou de exercer um papel meramente "analítico" em relação ao crime, à criminalidade e ao criminoso, tendo em vista que consegue apontar, por meio da crítica, problemas de método e aplicação, passando a ser capaz de criticar o próprio Direito Criminal, a Dogmática Penal e o próprio dogmatismo. Trata-se, sim, de uma ciência autônoma.

A lei criminal se preocupa com a criminalidade, mas aqueles que lidam com o Direito Penal também tem de lidar com ela, e devem conhecer, ao lado das normas jurídico-legais, a sua interpretação. Quem desconhece o aspecto empírico da administração da Justiça Criminal não pode lidar com as regras normativas do Direito Penal material (HASSEMER; MUÑOZ CONDE, 1989, p. 26-27).

O conhecimento do crime também é necessário para elaborar e aplicar as leis. Não é possível afirmar que o legislador penal está interessado apenas no conhecimento da criminalidade, pois entende que o Direito Penal não se aplica apenas aos interessados no conhecimento do crime. Desse modo, nas duas fases, torna-se indispensável conhecer ambas (HASSEMER; MUÑOZ CONDE, 1989, p. 27).

A distinção entre criminalidade e crime é razoável do ponto de vista conceitual. Seu valor prático, todavia, é limitado, pois destaca que o comportamento criminoso, como objeto do Direito Penal, tanto é um fenômeno social (criminalidade) quanto individual (crime), "[...] por cuja

\footnotetext{
A respeito do modelo integrado de Ciência Penal ver: ANDRADE, Vera Regina Pereira de. Dogmática e Sistema Penal: em busca da segurança jurídica prometida. Florianópolis: CPGD/UFSC, 1994. Tese de Doutorado; BARATTA, Alessandro. Criminologia y dogmática penal: pasado y futuro del modelo integral de la ciencia penal. In. MIR PUIG, Santiago et. al. Politica Criminal y Reforma del Derecho Penal. Bogotá: Temis, 1982, p. 28-63; ZAFFARONI, Eugenio Raúl. La critica al Derecho Penal y el porvenir de la Dogmática Jurídica. In: CUESTA, Jose Luis de la et. al. (Comp.). Criminologia y Derecho Penal ao servicio de la persona. Libro-Homenage al profesor Antonio Berinstain. San Sebastián: Instituto Vasco de Criminologia, 1989.
}

Revista de Direito Brasileira | Florianópolis, SC | v. 26 | n. 10 | p. 471-483 | Mai./Ago. 2020 
descrição e explicação são competentes Ciências Sociais e humanas" (HASSEMER; MUÑOZ CONDE, 1989, p. 27-28).

Além disso, pode indicar que, estatisticamente, a criminalidade é "a soma de todos os crimes", bem como que, em sua gênese, é algo diferente, pois, na origem e na evolução do crime, incide uma quantidade maior de fatores (históricos, culturais, sociológicos, econômicos etc.), representado pelo comportamento individual (HASSEMER; MUÑOZ CONDE, 1989, p. 28).

O crime, porém, não pode ser explicado somente a partir do ponto de vista das Ciências Sociais ou das Ciências Humanas, apesar de existirem e terem existido teorias sociológicas "dominantes" sobre o crime, bem como houve e ainda há tentativas das Ciências Humanas de explicar as causas da criminalidade (HASSEMER; MUÑOZ CONDE, 1989, p. 28-29).

Não se pode atribuir o crime à jurisprudência criminal, nem a criminalidade à legislação penal. Assim, o juiz criminal precisa, para julgar, conhecer a conduta individual, assim como o legislador penal necessita conhecer as condições e os desenvolvimentos sociais que influenciam o crime. Ocorre que esses conhecimentos são insuficientes para ambos (HASSEMER; MUÑOZ CONDE, 1989, p. 29).

O legislador penal também precisa de informações sobre as motivações que são esperadas das pessoas que, ilegalmente detidas, descobrem que sofrerão pena simbólica, bem como o juiz criminal precisa saber as reações esperadas da sociedade quando proíbe um criminoso de retornar ao lugar em que cometeu o delito ou onde a vítima ou sua família reside (HASSEMER; MUÑOZ CONDE, 1989, p. 29). ${ }^{4}$

Uma das razões pelas quais, a partir do final do século XX, têm sido criticadas a práxis e a Ciência do Direito Criminal, bem como a formação acadêmica do jurista, é a carência de (in)formação sobre a criminalidade daqueles que têm de lidar com a lei criminal, o que motivou, na Educação Jurídica, o aumento do interesse pela criminalidade como objeto do Direito Penal (HASSEMER; MUÑOZ CONDE, 1989, p. 30-31).

O conceito de "comportamento criminoso" é diferente no Direito Penal e na Criminologia, pois aquele observa o crime ("comportamento desviante") sob um prisma diferente em relação a esta, em decorrência das diferentes funções que cada uma das disciplinas tem que cumprir (HASSEMER; MUÑOZ CONDE, 1989, p. 77).

$\mathrm{O}$ interesse teórico da Criminologia é predominantemente científico. Interessa-se por questões como os fatores da criminalidade ou criminalização, v.g., dados sobre falta de moradia, desemprego ou anomalias psicológicas. Mesmo os criminologistas que aceitam o conceito legal de crime como ponto de partida, usam-no em sentido diverso daquele dado pela lei penal (HASSEMER; MUÑOZ CONDE, 1989, p. 77-78).

A Criminologia, diferentemente do que ocorre com o Direito Penal pode conceber vários conceitos de crime, de acordo com a orientação ou o interesse científico no qual se baseia, e.g., biológico-antropológico, interacionista ou macrossociológico, inteiramente desconectados do direito positivo de qualquer país (HASSEMER; MUÑOZ CONDE, 1989, p. 78).

Já o Direito Penal está ligado diretamente às leis nacionais, e é considerado “onipresente". O conceito de crime oferecido pela lei penal é unitário e tem o dever de descrever a conduta criminal, também, de forma unitária. A história recente demonstra que o conceito jurídico de crime é caracterizado pela plenitude, pela precisão e pela uniformidade (HASSEMER; MUÑOZ CONDE, 1989, p. 78-79).

A Criminologia não mais se encontra, no contexto de um modelo integrado das Ciências Penais, no lugar de "subciência", cujo objeto seria, apenas, o apontamento analítico das questões

4 “"...] o artigo 67 do Código Penal Espanhol autoriza os tribunais a impor a parte culpada de um crime contra as pessoas a proibição de retornar ao lugar onde há cometeu o delito ou no qual a vítima ou sua família reside, "comparecer a seriedade do ato e o perigo que o ofensor representa"'. (HASSEMER; MUÑOZ CONDE, 1989, p. 29)

Revista de Direito Brasileira | Florianópolis, SC | v. 26 | n. 10 | p. 471-483 | Mai./Ago. 2020 
relacionadas ao criminoso, ao crime, à criminalidade e aos tipos penais incriminadores. Por isso é que passou a ocupar uma nova posição no referido modelo.

\section{O PAPEL DA CRIMINOLOGIA NO "NOVO" MODELO INTEGRADO DE CIÊNCIAS PENAIS}

A Dogmática Penal distanciada da realidade exposta pela Criminologia torna-se estanque, divorciada das constantes modificações que impõem a (re)construção das políticas públicas em geral. Um novo modelo integrado entre as Ciências Penais, contudo, poderia ser capaz, ao menos, de amenizar essa situação de descompasso com as demandas sociais.

Nesse sentido, Baratta propõe um "novo modelo integrado", no qual confluem a dogmática, a teoria e a Sociologia do Direito Penal, ${ }^{5}$ porém, sob a perspectiva da Criminologia Crítica. Diferentemente do modelo positivista proposto por Liszt, o ponto de vista criminológico deixa de ser interno, distanciando-se do papel auxiliar da Criminologia Etiológica (BARATTA, 2004, p. 166).

A adoção do "ponto de vista externo" ao sistema penal significa que as definições do comportamento criminoso que são o produto desse sistema não são mais consideradas como ponto de partida, mas, sim, como problema e objeto de estudo, a partir do qual se utilizam a história e a análise da estrutura social (BARATTA, 2004, p. 169-170).

Com base neste novo paradigma a Criminologia em sua vertente denominada Criminologia Crítica, ocupa-se hoje da "análise dos sistemas punitivos em suas manifestações empíricas, em sua organização e em suas funções reais."(BARATTA: 1987, 624). Incluindo nessa perspectiva o processo de criminalização que vai desde a seleção dos bens e valores a serem tutelados pelo Direito Penal, a seleção realizada pelas agências policiais e judiciais dos que serão criminalizados, até a estigmatização do indivíduo que já tenha passado pela prisão.

A interdisciplinaridade contribui para a construção do novo modelo integrado por meio de várias outras ciências. A natureza e o conteúdo desse modelo são determinados pela intervenção da Criminologia Crítica no núcleo original do discurso, por meio da análise dos processos sociais e institucionais de definição de crime e reação social (BARATTA, 2004, p. 170).

$\mathrm{O}$ atual Sistema de Justiça Criminal não define satisfatoriamente o universo de situações e comportamentos "criminosos", até porque essa referência não é nem exclusiva, nem ontologicamente necessária, de modo que é inadequado para o estudo das variáveis relevantes para os propósitos de controle externo do sistema (BARATTA, 2004, p. 172).

Nesse "novo modelo integrado das Ciências Penais", se o objeto do discurso criminológico é o Sistema de Justiça Criminal, a Criminologia Crítica contribui para sua formação, que passa a funcionar como um modelo de controle interno do Sistema Jurídico-Penal (BARATTA, 2004, p. 173).

A teoria e a Sociologia do Direito Penal podem, então, justificar epistemologicamente a sua autonomia e a sua competição, de modo a que possa selecionar e organizar, dentro do próprio discurso, elementos de outros conhecimentos específicos, o que corrobora sua interdisciplinaridade interna (BARATTA, 2004, p. 173-174). ${ }^{6}$

5 "No interior da sociologia jurídica contemporânea, o setor que procuramos definir como Sociologia do Direito Penal se apresenta, no que é dado encontrar nos mais recentes desenvolvimentos, em diversos países, e não por último na Itália, como um dos pontos mais avançados de toda nossa matéria, neste processo de recuperação da dimensão macros sociológica para a interpretação crítica dos fenômenos estudados. Isto decorre, em boa parte, é um dever afirmá-lo, por atração dos mais recentes e mais positivos desenvolvimentos da sociologia criminal: tão estreitas são hoje, conforme se observou, as relações da sociologia jurídico-penal com esta disciplina". (BARATTA, 2002, p. 27).

6 "Poderíamos chamar a interdisciplinaridade externa ou a pluridisciplinaridade de uma forma de convergência entre disciplinas científicas e conhecimento especial com competição equivalente". (BARATTA, 2004, 174).

Revista de Direito Brasileira | Florianópolis, SC | v. 26 | n. 10 | p. 471-483 | Mai./Ago. 2020 
A articulação dos diferentes elementos do conhecimento viria a depender da natureza dos problemas que o discurso científico tenta controlar, bem como no que concerne à dinâmica das diferentes disciplinas e da percepção dos problemas pelos atores sociais, politicamente responsáveis pela elaboração de estratégias de controle social (BARATTA, 2004, p. 174).

O controle externo do Sistema de Justiça Criminal e a implementação de uma política coerente de resposta a situações problemáticas requer que redes sejam formadas pela convergência de saberes diferenciados e móveis, de acordo com a interdisciplinaridade externa, de modo a contribuir para uma ciência integral do Direito Penal (BARATTA, 2004, p. 174-175).

Essa assertiva ganha importância em face da influência das tecnologias da informação no cotidiano da humanidade. "As instituições sociais modernas são, sob alguns aspectos, únicas diferentes em forma de todos os tipos de ordem tradicional" (GIDDENS, 2011, p. 13). A Sociologia e a Criminologia passam a ser relevantes para o enfrentamento de questões que se encontram ao entorno da sociedade contemporânea.

A capacidade de sistemas computacionais processarem dados e informações permitem elencar megatendências que impactam as relações sociais, em cujo contexto se inserem a inteligência artificial, veículos autônomos, impressão em 3D, internet das coisas, biotecnologia, etc., exigindo-se adequação do Direito a essas novas realidades (SCHWAB, 2016, p. 10).

Assim, o novo modelo de Ciências Penais integradas é caracterizado pela interdisciplinaridade externa, de modo que a Criminologia ocupa um espaço qualitativamente idêntico ao da Dogmática Penal e da Política Criminal, de maneira a que seja possível tratar o a criminalidade como o fenômeno complexo que é.

A Dogmática Penal somente poderá evoluir se puder levar em conta o trabalho da Criminologia, a partir da mediação à qual procede a Política Criminal, que se volta, especialmente, a esclarecer quais são as finalidades e quais são os efeitos esperados pela aplicação do Direito Penal (DIAS, 1999, p. 23).

A partir da cooperação entre as ciências, "[...] substitui-se a ignorância mútua própria de frères ennemis", resultando em soluções justas e adequadas ao sistema jurídico-penal, que "[...] supõe a 'penetração axiológica' do problema penal, que, no campo da dogmática, tem de ser feita buscando-se valorações político-criminais” (DIAS, 1999, p. 29-35).

Em decorrência da convergência entre a Criminologia, a Política Criminal e a Dogmática Penal, estabelece-se um modelo capaz de tratar o fenômeno criminal em sua inteireza. Estabelecese, assim, algo como uma "relação circular" entre as disciplinas, de modo que uma complementa o objeto da outra.

Assim, a Criminologia fornece o substrato analítico do fenômeno criminal aos operadores do Sistema Jurídico-Penal, a Política Criminal transforma as análises e as orientações da Criminologia em opções e estratégias concretas, enquanto o Direito Penal converte o saber criminológico, aplicado pela Política Criminal, em normas positivas (GUINDANI, 2005, p. 10).

Essa modificação paradigmática no objeto e no conteúdo da Criminologia, como "Sociologia do Direito Penal", fez com que assumisse o papel de protagonista no novo modelo integrado de Ciências Criminais, de modo que o ensino da Dogmática Penal não pode ocorrer desvencilhado dessa ciência.

\section{O ENSINO DA CRIMINOLOGIA CRÍTICA NOS CURSOS DE DIREITO A PARTIR DO “NOVO” MODELO INTEGRADO DE CIÊNCIAS PENAIS}

O dogmatismo e o apego ao formalismo e ao direito codificado é parte integrante do ensino do Direito no Brasil, desde suas origens, inclusive, no que concerne à metodologia empregada na Educação Jurídica, desde os primeiros Cursos, instituídos ainda durante o Período Imperial. 
A finalidade das primeiras instituições de Educação Jurídica era a formação de jovens da elite econômica para o exercício de funções públicas, de modo a "[...] avalizar a conservação da classe influente no domínio", de modo que o ingresso nos Cursos de Direito era limitado aos “"herdeiros' do poder" (SANCHES; DOBARRO, 2016, p. 34-35).

Nesse mesmo cenário elitista difundia-se e aplicava-se um "ensino bancário", no qual o docente "colocava" os conhecimentos que pensava serem os corretos, passando o estudante, exclusivamente, a memorizar e repetir esses conceitos, formando, assim, profissionais alheios ao contexto social (SANCHES; DOBARRO, 2016, p. 35).

O formalismo jurídico repercutia, diretamente, portanto, na própria metodologia de ensino do Direito, que se voltava à transmissão e à memorização de conceitos legislativos e dogmáticos, de modo a conseguir criar um verdadeiro exército de burocratas, cuja real função era a manutenção do status quo.

Com a República, o Curso de Direito passou a destinar-se à formação de bacharéisadvogados. Continuava, porém, com o objetivo de formar uma "elite institucional e política brasileira", uma verdadeira "elite do pensamento humanístico" e, além disso, a "elite administrativa brasileira" (BASTOS, 1997, p. 37).

Desse modo, após o Período Imperial, mesmo com a modificação de seu objetivo original, os Cursos de Direito mantiveram o elitismo de suas origens, voltando-se, todavia, à formação de verdadeiros "operários da lei”, bem como permaneceu a metodologia de ensino de suas origens.

Assim, a Educação Jurídica brasileira ainda se encontra preso às tradições coimbrãs, com aulas discursivas, dogmatismo excessivo, ausência de correlação do currículo com a realidade social, ausentes os debates sobre do direito posto, a formação ética e a percepção da natureza, das funções e dos objetivos das carreiras jurídicas, por exemplo (MACHADO, 2003, p. 386).

Aos Cursos de Direito importa, pois, a propagação do direito codificado e do conteúdo dos manuais e cursos relacionados a cada um de seus "ramos". Pouco importa, desse modo, a efetividade da legislação no mundo fenomênico, que é o contexto que os ditames legais deverão regular e pacificar.

Essa "descontextualização" se refere, especialmente, à equiparação entre Direito e lei, que faz com que percam espaço e sentido quaisquer posturas questionadoras ou críticas, pois faz com que caiba ao agente jurídico apenas estudar e manipular um universo conceitual, dogmaticamente construído e transmitido, previamente delimitado e restrito à lei posta (SANTOS, 2002, p. 53-54).

Nesse diapasão, o saber jurídico transforma-se em algo como um "conhecimento hermético", que permanece alheio ao ambiente que o circunda, ou seja, um saber que, "[...] infenso às práticas sociais que o circunscrevem, resta estagnado, a-histórico, descontextualizado" (SANTOS, 2002, p. 54).

Confirma-se, assim, que o Curso de Direito se volta à formação de profissionais que, alheios à complexidade social e à própria realidade, dedicar-se-ão a manter do status quo e a diferenciação entre as classes, por intermédio da aplicação acrítica dos códigos e do apego ao dogmatismo.

Até porque o direito liberal é a expressão normativa dos interesses de classes, objetivados em codificações que resultam da "vontade geral", abstraída de interesses antagônicos, reproduzidos, de forma meramente descritiva, pelas escolas e manuais, nos quais as investigações científicas têm os códigos como dados inquestionáveis (MACHADO, 2009, p. 58).

Assim, o Direito apresenta uma dimensão ideológica, internalizada na estrutura normativa estatal. O processo de conhecimento do fenômeno jurídico é puramente normativista. A reprodução do saber jurídico é pautada por paradigmas epistemológicos igualmente ideologizados (MACHADO, 2009, p. 58-59).

Essas atitudes teóricas resultam na completa despolitização do saber jurídico e no esvaziamento do seu sentido ético-transformativo, o que transfigura as Escolas de Direito em verdadeiros "aparelhos ideológicos da burguesia", pois realizam, automaticamente, a difusão dos 
valores, objetivos e aspirações da classe detentora do poder econômico, social e político (MACHADO, 2009, p. 144).

A Educação Jurídica está pautada no paradigma epistemológico normativo-positivista, e a sua prática pedagógica está embasada no método lógico-formal. Ambos proporcionam ao jurista um conhecimento meramente descritivo da ordem jurídica, bem como resultam na aplicação técnico-burocrática e desumanizada do Direito (MACHADO, 2009, p. 144-145).

Mais do que uma característica, a metodologia "bancária", derivada do formalismo impregnado na Educação Jurídica, é resultado direto do próprio dogmatismo, a partir da pretensão de correção do direito codificado, dirigida à manutenção do status quo, sob o disfarce da ilusão de segurança jurídica.

O iluminismo político-jurídico necessita do mito, pois "precisa de um absoluto ao qual se agarrar; o mito cobre nobremente a carência de absoluto que foi colocada em prática e preenche um vazio que poderia se tornar arriscadíssimo para a estabilidade da nova estrutura da sociedade civil” (GROSSI, 2007, p. 51-52).

É justamente nisso que consiste o dogmatismo que contamina o ensino do Direito: a busca desesperada pela estabilidade das relações sociais, como se esta equivalesse à segurança jurídica. De modo a conservar essa útil ilusão, os Cursos de Direito continuam se baseando no direito legislado e nos limitados manuais.

Por isso é que os profissionais formados pela Educação Jurídica não cumprem o seu devido papel que, muitas vezes, desconhecem. A vivência do fenômeno jurídico parte da premissa de uma "nova pedagogia jurídica", que pressupõe a (re)conscientização dos docentes e discentes sobre o papel que devem exercer na sociedade (MAROCCO, 2012, p. 77-85).

A formação do profissional do Direito deveria se voltar às inovações, para além do processo judicial e de suas formalidades, pois tem de compreender novas teorias, de modo a conseguir construir novos paradigmas: “[...] apesar dos vários modelos procedimentais que buscam reduzir as conflitualidades sociais e jurídicas, as inovações eficazes ainda são raras" (MAROCCO, 2012, p. 85-102).

Assim, por mais que os professores tentem ensinar criticamente o Direito, por intermédio de estudos de caso e metodologias educativas inovadoras, o currículo do Curso de Direito resta agrilhoado às exigências da Administração Pública Federal, que ainda entende que o Direito se encontra repartido, de maneira estanque, em "ramos" isolados.

As disciplinas devem ser integradas e têm de se voltar a incentivar o conhecimento interdisciplinar e a interação entre si, devendo considerar o aparecimento de novos grandes temas como eixos integradores do conhecimento e da prática, por meio da utilização das áreas de conhecimento das disciplinas (MASETO; ZUKOWSKY-TAVARES, 2013, p. 79-80).

Nesse sentido, a organização curricular não pode ser construída a partir das disciplinas, mas, sim a partir de "problemas profissionais contextualizados", de modo a que partam de algo concreto: "[...] abstrai-se um caminho para a sistematização teórica e, após, retorna-se à concretude, porém, transformada" (MASETO; ZUKOWSKY-TAVARES, 2013, p. 80).

As organizações curriculares devem estruturar-se a partir da vivência de "experiências problematizadoras e integradoras", que alternem a vivência e a sistematização do conhecimento produzido, de modo a permitir o diálogo entre distintas as várias disciplinas, de forma a ser possível substituir os atuais "desenhos curriculares" (MASETO; ZUKOWSKY-TAVARES, 2013, p. 8081).

Se assim não o for, os profissionais do Direito continuarão a reproduzir a legislação e os dogmas, ao invés de (re)construir a realidade jurídico-social, que é o seu verdadeiro papel. O quadro atual dos Cursos de Direito - bem como o formato dos exames e concursos públicos para as carreiras jurídicas - evidencia que se procura a apatia, a obediência e a neutralidade.

Neutralidade essa que é filha do status quo: dá-lhe "campo livre" para se recusar a tomar alguma atitude. O Curso de Direito, breve, superespecializado e tecnicista, é curto de visão e 
"encolhido no tempo": cria apenas "pseudo-especialistas do tipo subalterno", ensinando aos alunos as técnicas "suficientes" para que se torne um profissional "bonzinho e bem-mandado" (LYRA FILHO, 1981, p. 17).

Nesse sentido, a metodologia aplicada nos Cursos de Direito "[...] dá tributo à estrutura assente, que pede mão-de-obra, sem cabeça", pois os estudantes são deixados "[...] aos dúbios cuidados de não rigorosos especialistas e constantes repetidores do positivismo, de várias espécies" (LYRA FILHO, 1981, p. 17-55).

A Criminologia brasileira estava a reboque do Direito Criminal dogmático, pois, no Brasil, campeava a atitude dogmática. Por isso é que surgiam obras de mérito, erudição e preocupações positivas no terreno jurídico-penal. Apesar disso, subsiste o desfibramento da produção dos “criminólogos" brasileiros (LYRA FILHO, 1981, p. 55).

Desse modo, também a Criminologia é vítima da Educação Jurídica "especializada", que ainda pensa a referida ciência como mera "auxiliar" do Direito Penal, não como a ciência autônoma que verdadeiramente é. Isso porque, enquanto "Sociologia do Direito Penal", o saber criminológico se encontra em contato direto com a realidade.

Ocorre que a experiência de ensinar a "pensar certo" deve se afastar da fala ou da prática puramente descritiva. Deve ser "[...] algo que se faz e que se vive enquanto dele se fala com a força do testemunho", de modo que "[...] implica a existência de sujeitos que pensam mediados por objeto ou objetos sobre que incide o próprio pensar dos sujeitos” (FREIRE, 1996, p. 41).

Assim, "pensar certo" não corresponde a um "[...] fazer de quem se isola, de quem se 'aconchega' a si mesmo na solidão, mas um ato comunicante". Por isso é que não se pode "[...] pensar sem entendimento e o entendimento, do ponto de vista do pensar certo, não é transferido, mas coparticipado". Até porque, o "pensar certo" é dialógico, não polêmico (FREIRE, 1996, p. 4142).

O sujeito que "pensa certo" não deve transferir, depositar ao outro, que se tornaria "paciente de seu pensar", a inteligibilidade das coisas, dos fatos ou dos conceitos, mas, sim, exercer, como ser humano, "[...] a prática de inteligir, desafiar o educando com quem se comunica e a quem comunica, produzir sua compreensão do que vem sendo comunicado" (FREIRE, 1996, p. 42).

No contexto do novo modelo integrado de Ciências Penais, a Criminologia não só é a responsável por manter o Direito Penal em contato com a realidade, como, enquanto "Sociologia do Direito Penal", tem o papel de criticar os dogmas e os dispositivos legais e de medir, quantitativa e qualitativamente, a sua efetividade.

Assim como as Criminologias Críticas têm pouco espaço na Criminologia, a disciplina "Criminologia" ocupa pouco espaço na Educação Jurídica, pois, no "modelo integrado" consolidado sobre os pilares interdependentes do Direito Penal, da Criminologia e da Política Criminal, há uma divisão metodológica, na qual a função papel da Criminologia é "auxiliar" (ANDRADE, 2012, p. 342).

O Direito Penal, ensinado à luz da Dogmática Penal, ocupa um lugar central e espaçoso. É o debate sobre as relações entre Direito Penal e Criminologia e a performance que deveriam assumir no "modelo integrado de Ciências Penais" que permite compreender o status "ausenteperiférico" da Criminologia (ANDRADE, 2012, p. 342-343).

A Criminologia passou a julgar o Direito Penal, de modo que a inserção, o espaço e a definição de seu conteúdo no ensino do Direito envolvem um conjunto de definições paradigmáticas e políticas, que transferem suas marcas ao ensino, que têm impacto na construção de subjetividades que impactam a vida social (ANDRADE, 2012, p. 345).

Ensinar Criminologias equivale a concorrer para a formação da consciência jurídica crítica e responsável, apta a transgredir “[...] as fronteiras sempre generosas do sono dogmático, da zona de conforto do penalismo adormecido na labuta técnico-jurídica, capaz de inventar novos caminhos 
para o enfrentamento das violências (individual, institucional e estrutural)" (ANDRADE, 2012, p. 346).

Desse modo, no atual modelo integrado das ciências criminais, caraterizado pela interdisciplinaridade externa, tendo a Criminologia se equiparado, em importância, à Política Criminal e ao Direito Penal, deve ser ensinada, nos cursos jurídicos, como uma forma de perceber o referido "ramo" do Direito em contato direto com a realidade.

\section{CONCLUSÃO}

Tendo em vista o Direito ser um fenômeno social complexo, deve ser estudado de acordo com esse enredamento, que se destaca em relação ao Direito Penal, responsável pelas ações humanas mais repudiadas pelo ordenamento jurídico e pelas garantias fundamentais do acusado.

Em decorrência dessa complexidade é que surgiu, a partir de Von Liszt, o "modelo das Ciências Penais integradas, que admite a insuficiência do dogmatismo para lidar com as questões criminais, somando o Direito Penal à Política Criminal e à Criminologia, esta, porém, vista pelo viés etiológico, como "ciência menor", enquanto a dogmática era seu "ponto de partida".

O modelo se preocupava, especialmente, com o crime e com a figura do criminoso. Por causa da "crise" da Criminologia Etiológica, o referido modelo decaiu, por não ser capaz de lidar com a complexidade social crescente. A Criminologia passou a exercer um papel central, como ciência autônoma, de crítica, relacionada ao Direito Penal, ao dogmatismo e à lei penal.

A Dogmática Penal é incompleta se estiver distante da Criminologia, que está apta a perceber e demonstrar as constantes modificações advindas da complexidade. Por isso é que surgiu um novo modelo integrativo, caracterizado pela interdisciplinaridade externa, no qual a Criminologia ocupa um papel central, ao lado do Direito Penal e da Política Criminal.

Dessa convergência entre as três ciências, estabelece-se algo como uma "relação circular", na qual uma disciplina complementa a outra. A partir desse novo modelo, porém, faz-se necessária uma radical modificação no ensino do Direito Penal, que ainda se encontra apegado ao dogmatismo originado ainda no início da Educação Jurídica no Brasil.

Como se encontra na atualidade, a Educação Jurídica, baseada no dogmatismo e em metodologias educacionais formalistas, volta-se à formação de "operários da lei", não de "operadores do Direito", componentes de uma "elite intelectual" cuja atuação busca a manutenção do status quo.

A Educação Jurídica deve se atinar à realidade, por meio da aplicação crítica dos códigos, com metodologias inovadoras, e com modificações significativas nas bases curriculares, que se voltem a trabalhar as complexidades sociais. Um dos componentes obrigatórios desse novo currículo deve ser o ensino da Criminologia.

Nesse sentido, de modo a dar concretude ao novo modelo integrado de Ciências Criminais a Criminologia deve ser ensinada como saber crítico, a partir do contato direto com a realidade, não como mera ciência "auxiliar" do Direito Penal, mas, sim, como saber autônomo, enquanto "Sociologia do Direito Penal".

\section{REFERÊNCIAS}

ANDRADE, Vera Regina Pereira de. Dogmática e Sistema Penal: em busca da segurança jurídica prometida. Florianópolis: CPGD/UFSC, 1994. Tese de Doutorado.

ANDRADE, Vera Regina Pereira de. Pelas mãos da Criminologia: o controle penal para além da (des)ilusão. Rio de Janeiro: Revan, 2012. 
BARATTA, Alessandro. Criminologia y dogmática penal: pasado y futuro del modelo integral de la ciencia penal. In. MIR PUIG, Santiago et. al. Politica Criminal y Reforma del Derecho Penal. Bogotá: Temis, 1982, p. 28-63;

BARATTA, Alessandro. Principios de derecho penal mínimo. Para una teoría de los derechos humanos como objeto y limite de la ley penal. Doctrina Penal, Buenos Aires, n. 40, p. 623-650. 1987.

BARATTA, Alessandro. Nuevas reflexiones sobre el modelo integrado de las ciencias penales, la política criminal y el pacto social (1998). In: ELBERT, Carlos Alberto. (Org.). Criminología y sistema penal. Buenos Aires; B de F, 2004, p. 168-192.

BARATTA, Alessandro. Criminologia Crítica e crítica do Direito Penal. 3. ed. Rio de Janeiro: Revan, 2002.

BASTOS, Aurélio Wander. O ensino jurídico no Brasil e as suas personalidades históricas: uma recuperação de seu passado para reconhecer seu futuro. In: BRASIL. Conselho Federal da OAB. Ensino jurídico: 170 anos de cursos jurídicos no Brasil. Brasília: Conselho Federal da OAB, 1997, p. 35-55.

CONSELHO FEDERAL DA OAB. Ensino jurídico: 170 anos de cursos jurídicos no Brasil. Brasília: OAB, Conselho Federal, 1997.

DIAS, Jorge de Figueiredo. Questões fundamentais do Direito Penal revisitadas. São Paulo: RT, 1999.

ELBERT, Carlos Alberto. (Org.). Criminología y sistema penal. Buenos Aires; B de F, 2004.

FREIRE, Paulo. Pedagogia da autonomia: saberes necessários à prática educativa. São Paulo: Paz e Terra, 1996 (Coleção Leitura)

GHIRARDI, José Garcez; FEFERBAUM, Marina Feferbaum. Ensino do direito em debate: reflexões a partir do $1^{\circ}$ Seminário Ensino Jurídico e Formação Docente. São Paulo: Direito GV, 2013

GIDDENS, Anthony. As consequências da modernidade. São Paulo: UNESP, 2011.

GROSSI, Paolo. Mitologias jurídicas da modernidade. Florianópolis: Fundação Boiteux, 2007.

GUINDANI, Miriam Krenzinger. Sistemas de Política Criminal: retórica garantista, intervenções simbólicas e controle social punitivo. Cadernos CEDES/IUPERJ, v. 01. p. 01-19, 2005.

HASSEMER, Winfried; MUÑOZ CONDE, Francisco. Introducción a la criminología y al derecho penal. Valencia: Tirant lo Blanch, 1989.

LYRA FILHO, Roberto. Problemas atuais do ensino jurídico. Brasília: Obreira, 1981.

MACHADO, Antonio Alberto. Ensino jurídico e mudança social. São Paulo: Expressão Popular, 2009. 
MACHADO, Rubens Approbato. Advocacia e democracia. Brasília: OAB Editora, 2003.

MAROCCO, Andréa de Almeida Leite. O ensino jurídico: desafios à formação do profissional do século XXI. In: RODRIGUES, Horácio Wanderlei; ARRUDA JÚNIOR, Edmundo Lima de. (Org.). Educação jurídica. 2. ed. Florianópolis: FUNJAB, 2012, p. 73-122.

MASETO, Marcos Tarciso; ZUKOWSKY-TAVARES, Cristina. Inovação e a universidade In: GHIRARDI, José Garcez; FEFERBAUM, Marina Feferbaum. Ensino do direito em debate: reflexões a partir do $1^{\circ}$ Seminário Ensino Jurídico e Formação Docente. São Paulo: Direito GV, 2013, p. 33-46. (Série Pesquisa Direito GV)

MEYER-PFLUG, Samantha Ribeiro; SANCHES, Samyra Naspolini. O paradigma dogmático da ciência jurídica nos manuais de ensino do direito. Universitas Jus. v. 27, n. 3., p. 1-9. 2016. Disponível em: https://www.publicacoesacademicas.uniceub.br/jus/article/view/2361. DOI: http://dx.doi.org/10.5102/unijus.v24i2.2361.

PEREIRA, José Hygino Duarte. Prefácio. In: VON LISZT, Franz. Tratado de Direito Penal Allemão. Tomo I. Rio de janeiro: F. BRIGUIET \& C, 1899, p. XXIX-XXX.

RODRIGUES, Horácio Wanderlei; ARRUDA JÚNIOR, Edmundo Lima de. (Org.). Educação jurídica. 2. ed. Florianópolis: FUNJAB, 2012

SANTOS, André Luiz Lopes dos. Ensino jurídico: uma abordagem político-educacional. São Paulo: Edicamp, 2002.

SCHWAB, Klaus. A quarta revolução industrial. Bauru: Edipro, 2016.

SILVEIRA, Vladmir Oliveira; SANCHES, Samyra Haydêe Dal Farra Naspolini. A reprodução do paradigma dogmático da ciência do direito no ensino jurídico e a necessidade de mudança na pesquisa jurídica que permitam uma efetiva educação jurídica. IN: SILVEIRA, Vladmir Oliveira; SANCHES, Samyra Haydêe Dal Farra Naspolini; COUTO, Mônica Bonetti. Educação Jurídica. São Paulo, Saraiva, 2013. p. 497-514.

VON LISZT, Franz. Tratado de Direito Penal Allemão. Tomo I. Rio de janeiro: F. BRIGUIET \& C, 1899.

YOUNG, Jock. A sociedade excludente: exclusão social, criminalidade e diferença na modernidade recente. Rio de Janeiro: Revan, 2002.

ZAFFARONI, Eugenio Raúl. La critica al Derecho Penal y el porvenir de la Dogmática Jurídica. In: CUESTA, Jose Luis de la et. al. (Comp.). Criminologia y Derecho Penal ao servicio de la persona. Libro-Homenage al profesor Antonio Berinstain. San Sebastián: Instituto Vasco de Criminologia, 1989. 